BAND 14. N:o 10.

\title{
Parasitic copepods from Japan, including five new species.
}

By

\author{
CHARLES BRANCH WILSON. \\ Ph. D., Westfield, Massachusetts, U. S. A.
}

With 4 Plates.

Communicated October 12th 1921 by HJ. Théel and E. Lönnberg.

\section{Introductory.}

The specimens included in the present paper were collected by Dr. Sixten Bock during an expedition to Japan in 1914. There are nine vials of which two are duplicates, leaving seven different species, and of these five prove to be new to science. The specimens are all excellently preserved and are deposited in the Riksmuseum at Stockholm, where they will serve as types of the new species.

This collection forms a valuable addition to our knowledge of the Japanese fish parasites since the only previous records have been a few species collected at random over a long period of years.

Even the two species which are not new give us different localities and hosts and thus add materially to the species distribution.

Argulus caecus New Species. Pl. 1, figs. 1-5.

Host and record of specimens. A single female was obtained from Fujita's Colony at Aburazubo, Misaki, Sagami, 
Japan, May 28, 1914. Depth: 2-3 m. The large size of this specimen and its excellent preservation more than compensate for the lack of duplicates.

Specific characters of female. Carapace obovate, onethird longer than wide, considerably narrowed anteriorly, widest through the fourth thorax segment, and entirely concealing the swimming legs. Posterior sinus narrow, one-half the length of the carapace, evenly rounded at the base, with nearly parallel sides. Cephalic area in the form of a spherical triangle, the anterior shorter side close to the frontal margin of the carapace.

The longitudinal chitin rods are well-defined and rather strongly curved, but neither the dorsal brain nor the eyes are visible.

From either side of the cephalic area near its posterior end a groove runs diagonally outward and forward toward the margin of the carapace.

From about the center of this groove a longitudinal branch runs backward along the center of each lateral lobe nearly to the posterior end.

The respiratory areas in the lateral lobes are near the anterior ends; the front area is elliptical in outline, a little smaller than the sucking disk, and partially concealed by the latter. The posterior one is separated by a considerable interval from the anterior one and is club-shaped, its posterior end being somewhat enlarged.

The abdomen is elliptical, as wide as long; the posterior sinus is slitlike, less than one-third the length of the abdomen, and the anal laminae are basal. The first antennae have strong hooks on the anterior and lateral margins, and a stout spine on the posterior margin.

Each second antenna has two spines at its base, the outer one considerably smaller than the inner; there is also another larger spine on the ventral surface of the head, behind the base of each antenna.

The sucking disks are placed far forward, just behind the lateral sinuses; each is about one-sixth the greatest width of the carapace, or a little less than one-third the width at the level of the disks themselves. The supporting ribs of the margins of these disks are very complicated, as 
can be seen from fig. 3. Each is composed of about 30 overlapping chitin disks or plates; those at the base are somewhat smaller than those in the center, while those at the tip diminish rapidly in size until the last ones are reduced to mere dots. Each disk is more or less elliptical in outline, and those at the base have a semielliptical puncture in their basal half. The size of these punctures diminishes toward the center of each rib, and they wholly disappear a little beyond the center.

Basal joint of the maxillipeds much larger than the other three joints combined and triangular in shape. The basal plate is at the posterior angle and only covers the space beneath the papillated area, not reaching to the anterior margin. On its posterior margin at the inner corner is a large sharp spine and just outside of it another smaller one. The remainder of the posterior margin is smooth, but at the outer corner is a tiny papilla, the rudiment of the third spine. The papillated area is abruptly raised from the surface of the basal joint and resembles a piece of thick felt fastened to the joint. The same is true of the areas at the distal ends of the basal and second joints. These areas are armed with spines and hairs, so small as to be almost invisible.

The anterior legs have large swimming flagellae, the other three pairs have none. The basal joints of the fourth pair are small and have tiny lobes, without any distinct heel.

Color (preserved material) dark yellowish brown, with much lighter streaks along the grooves and ribs on the dorsal surface and around the margins of the carapace and abdomen. The ventral surface is a uniform yellowish brown, considerably lighter in tint.

Total length $19 \mathrm{~mm}$. Carapace $18.50 \mathrm{~mm}$. long, 12.50 mm. wide. Abdomen $5 \mathrm{~mm}$. long, $5 \mathrm{~mm}$. wide.

(caecus, blind, the eyes being invisible from the exterior)

Remarks. So far as is known this is the first species of the genus in which the eyes are wholly invisible in both dorsal and ventral views. This fact, together with the peculiar structure of the supporting rods in the sucking disks and of the maxillipeds, are the distinguishing characters of the species. It is worthy of note that the only species thus 
far reported as larger than the present one is A. scutiformis Thiele, taken from the outside surface of Tetraodon and Haliotus at Hakodate, Japan.

In that species the cephalic area is relatively much Jarger, the posterior lobes of the carapace are very much shorter, the posterior sinuses of both carapace and abdomen are shorter and the supporting ribs of the sucking disks differ greatly in structure.

Achtheinus japonicus New Species. Pl. 2, figs. 9-17.

Host and record of specimens. Four adult females and three younger ones but little beyond the chalimus stage were taken from the fin of Acanthias sp. at Misaki, Japan, May, 5, 1914. The adults become the types of the new species.

Unlike some of the other species of the genus they do not dig into the skin when attaching themselves. They simply insert the tips of the second antennae and the terminal claws of the maxillipeds, and hold on also with the pads on the latter appendages. In consequence they are more easily detached from their host than is usual in the genus.

Specific characters of female. General body form elongate, about twice as long as wide, and rather squarely truncated anteriorly and posteriorly. Carapace trapezoidal, widest across the posterior margin, with nearly straight sides. The anterior margin projects slightly between the frontal plates, while the posterior margin has a wide central lobe and narrow and rather pointed lateral lobes. The lateral areas are also narrow and no grooves are anywhere visible on the dorsal surface.

The dorsal plates of the fused second and third segments have a combined width equal to that of the carapace. Each is elliptical, much longer than wide, and the two are entirely separated along the midline. The plates of the fourth segment are considerably larger; each is orbicular, about as wide as long, and the two are fused at their bases; they overlap at the center and have a combined width equal to that of the genital segment. 
The latter is elliptical, a little longer than wide, with rather convex sides and very broadly rounded posterior lobes. The posterior sinus is obliterated by the overlapping of the posterior lobes. The egg strings are wide and about twice the length of the body.

The abdomen is one-jointed, triangular, twice as wide as long, and thoroughly fused with the anal laminae, the only line of demarkation being the notches in the lateral margins. The fifth legs are broadly conical and destitute of spines or setae.

The first antennae are two-jointed and sparsely armed with setae. The terminal claw of the second pair is stout, curved into the shape of a sickle, and armed with a long row of large teeth. The largest basal one is double, the others are single. The first maxilla is as wide as long, strongly narrowed toward the tip, which is armed with a long and stout spine having a swollen base. On the anterior margin of the maxilla are two small spines and on the posterior margin a minute process, tipped with a tiny spine.

In the maxillipeds the pad is of medium size and elliptical in outline, the terminal claw nearly straight and the process opposite the claw nearly as long as the claw itself.

In the swimming legs the rami of the first and second pairs are two-jointed and armed with setae. The rami of the third and fourth legs are one-jointed except the exopod of the third pair, which is two-jointed; the endopods are destitute of setae, the exopods are sparsely armed with them.

Color (preserved material) a uniform yellowish white.

Total length $6 \mathrm{~mm}$. Carapace $2.40 \mathrm{~mm}$. wide, $2.25 \mathrm{~mm}$. long. Genital segment $3 \mathrm{~mm}$. wide, $3.25 \mathrm{~mm}$. long. Egg strings $12.50 \mathrm{~mm}$. long.

(japonicus, belonging to Japan).

Specific characters of young female. Carapace acornshaped, nearly as wide as long, widest at the center, with long and sharp lateral lobes and a wide reentrant median lobe on the posterior margin. Frontal lobes indistinctly separated from the carapace by grooves, their outer ends very long and pointed. Second segment not yet fused with the third, its lateral margins projecting and notched near the anterior corner. Third and fourth segments each with 
a pair of rudimentary dorsal plates, widely separated. Genital segment a little more than half the width of the carapace, with straight lateral margins and well rounded posterior corners. Posterior sinus nearly one-third the width of the genital segment, and showing the whole abdomen in dorsal view. The anal laminae are relatively larger than in the adult and are furnished with much longer setae, which are plumose. Appendages and color the same as those of the adult.

Total length $3.40 \mathrm{~mm}$. Carapace $1.90 \mathrm{~mm}$. long, 1.80 $\mathrm{mm}$. wide. Genital segment $0.90 \mathrm{~mm}$. long, $1 \mathrm{~mm}$. wide.

Remarks. This new species differs from those hitherto described rather by an accumulation of lesser details than by any one prominent character. The complete closing of the posterior sinus of the genital segment is perhaps the most evident character. To this may be added the wicked tooth-barbs of the second antennae, the form and armature of the first maxillae, and the details of the swimming legs. In this species also the process opposite the terminal claw of the maxillipeds is as long as the claw itself.

Taeniacanthus coelus New Species. Pl. 3, figs. 18-26.

Host and record of specimens. Thirty females, most of them with egg cases, were obtained from an unknown host, probably an elasmobranchian fish, at Fujita's Colony, Misaki, Japan, May 28, 1914.

Many of them are still attached to soft epithelium apparently from the nasal cavity, in which they are partly buried. They do not, however, burrow at all into the tissue, but the soft folds rise up around their bodies, partly enveloping them. They attach themselves by drawing a fold of the soft skin into the cavity of the front of the cephalothorax and fastening into it the claws of the maxillipeds.

Specific characters of the female. General body form elongate and narrow, but with the abdomen relatively wider than in other species. Cephalothorax inclined ventrally at an angle of about 45 degrees to the body axis, the front squarely truncated and forming a slightly projecting margin 
around a deeply sunken pit. The first antennae lie along the anterior portion of this margin and just outside the base of each a stout hook or claw projects into the cavity of the pit. The first legs curve around the posterior portion of the margin, the two rami projecting outwardly.

The cephalothorax is transversely elliptical in dorsal outline, one-fifth wider than long, with evenly rounded margins. The thorax segments diminish regularly in width from the second to the fifth and entirely conceal the legs in dorsal view, except the fifth pair.

The genital segment is considerably narrower than the anterior portion of the fifth segment, but about the same width as the posterior portion; it is as wide as long and squarely truncated at either end.

The abdomen is composed of four segments, diminishing regularly in size backwards, except that the last one, though narrower than the others, is a trifle longer. The anal laminae are narrow, two-thirds the length of the last segment, each tipped with two long setae and having two shorter ones on the outer margin. The egg cases are attached to the dorsal surface of the genital segment; each is considerably wider than the genital segment itself and more than half the entire body length. The eggs are mumerous, arranged in ten or twelve rows, about 35 eggs in a row.

The basal portion of the first antennae is not much enlarged and is indistinctly divided into three parts, with a row of large flattened setae along its anterior margin. The terminal portion is made up of three distinct segments, heavily armed with smaller setae. The second antennae are three-jointed and tipped with three long curved claws, with two others on the dorsal margin of the terminal joint.

The anterior ventral surface of the cephalothorax is deeply reentrant, forming a sunken pit, upon whose anterior walls are located the second antennae and mouth parts, except the maxillipeds which are on the posterior walls. None of these appendages is visible until the pit has been cut out of the cephalothorax, slit down its sides, and then flattened out under a cover glass.

The upper lip is orbicular, about the same width and length, with a prominent knob on either side at the base. The mandibles are three-jointed, the two distal joints bent 
backward nearly at right angles to the basal joint, the terminal joint a simple curved spine. Each first maxilla is armed with two plumose setae, one directed ventrally and one laterally. The second maxillae are simple and nearly straight, terminating in a single spine. In the maxillipeds the terminal claw is folded back against the basal joint and there is a small accessory claw on the outer margin at the base of the terminal claw.

The first swimming legs have very wide rami which are heavily armed with flattened plumose setae, but each ramus is apparently one-jointed. The rami of the second, third and fourth legs are three-jointed, with the arrangement of spines and setae shown in the figures. The fifth legs are two-jointed, the terminal joint with but a single spine.

Color (preserved material) white, faintly tinged with brown.

Total length $3.20 \mathrm{~mm}$. Width of cephalothorax $1 \mathrm{~mm}$. Length of egg strings $1.90 \mathrm{~mm}$., width $0.36 \mathrm{~mm}$.

(coelus, sunken or pitted, alluding to the front of the cephalothorax).

Remarks. This species may be distinguished from the three already described as follows. From carchariae by the fact that the free segments of the thorax diminish regularly in size; from flagellans by the shape of the cephalothorax in dorsal view and by the fact that the cephalothorax is inclined only 45 degrees to the body instead of being at right angles to it; from albidus by the comparative size of the cephalothorax and the first three free thorax segments and by the details of the swimming legs.

It is also distinguished from them all by the deep pitting of the front of the cephalothorax, which is something unique in copepod anatomy.

Chondracanthus distortus New Species. Pl. 4, figs. 33-39.

Host and record of specimens. Two lots of this parasite were obtained. The first contains forty female specimens, nearly all with egg strings and each with one or more attached males. They were taken from the gills of Zeus japonicus captured May 13, 1914 in a depth of 110-115 fathoms 
at Sato-no-misaki, Kiuschiu, Japan. They are made the types of the new species. The second lot consists of a single female with an attached male and was taken from an unknown host, captured May 14, 1914, twenty-three miles $\mathrm{N}$. W. of Osesaki, one of the Goto Islands.

Specific characters of female. General body form short and stout; head large, three-fifths as wide as the body, orbicular, with two pairs of horns on the lateral margins, the anterior pair considerably shorter and narrower than the posterior ones. The entire body is fused, with the joints indicated by indentations on the lateral margins and by breaks in the longitudinal muscles. The anterior thorax is narrowed into a short neck behind the head with a single pair of soft lateral processes and a short, bluntly rounded horn on the dorsal surface on either side close to the lateral margin. The rest of the thorax has a row of soft processes along either lateral margin and around the posterior end. These are long and narrow and taper to a blunt point. The pair at the posterior corners are composite, made up of three rami, the central one of which is bifurcate. In the center of the posterior margin is a single, unpaired process, wider than the others and more acuminate.

The fused genital segment and abdomen are partially differentiated and project from the ventral surface of the thorax at its posterior end. They carry a single pair of similar soft processes.

The first antennae are of the usual form, soft, indistinctly segmented, enlarged at the base, and tapered to a rather blunt tip which is armed with a single tiny seta. The second antennae are in the form of stout chitin claws, considerably flattened dorsoventrally and bluntly pointed, with a pair of minute spines on the inner margin at the tip.

The mandible has the usual crescent-shaped cutting blade, armed with small needle-like teeth along both margins. The palp is very large and is attached to the posterior distal corner of the basal joint behind the cutting blade. It is composed of a single joint, acorn-shaped, the point of the acorn tipped with a single large spine. The maxilla has a narrow and somewhat curved cutting blade and a small conical palp, tipped with a single seta. The bladeterminates 
in a large conical tooth and has along the posterior margin a row of similar teeth, diminishing in size toward the base. The maxilliped has a large basal joint, a much smaller second joint, with a knob armed with spines on its inner distal corner, and a small curved terminal claw, with a small spine on its inner margin near the tip. The first and second swimming legs are quite small, each one-jointed, bifurcate, with the rami bluntly rounded. The egg strings are cylindrical, as long as the entire body, and very wide. They are not straight as in other species, but are curved in and out twice near the base, giving them a peculiar, distorted appearance sufficient to distinguish the species.

Color (preserved material) a uniform snow-white.

Total length, including soft processes, $6 \mathrm{~mm}$. Head 1.60 $\mathrm{mm}$. long, $1.25 \mathrm{~mm}$. wide. Thorax $2 \mathrm{~mm}$. wide. Egg strings $6 \mathrm{~mm}$. long, $1-1.25 \mathrm{~mm}$. wide.

Specific characters of male. First and second thorax segments fused with the head, the resultant cephalothorax evenly curved dorsally and projecting a little ventrally. Third segment free but poorly differentiated, the remaining segments fused with the genital segment into an ellipsoidal posterior body, terminated by two conical anal laminae, which are destitute of setae. Appendages like those of the female with the usual sexual variations: maxillae without teeth on the posterior margin, but with a palp. Swimming legs apparently lacking.

Total length $0.60 \mathrm{~mm}$. Cephalothorax $0.35 \mathrm{~mm}$. long, $0.30 \mathrm{~mm}$. thick.

(distortus, distorted, alluding to the egg strings).

Remarks. This species at first sight seems something like the type of the genus, $C$. zei, but differs from it in many particulars. It is only half the size, has a much smaller number of soft processes, only a single pair of which are bifurcate, and the egg strings are radically different in size and shape. Consequently, although it is a parasite of the same genus of fish, it must be credited as a new species.

The peculiar distortion of the egg strings is totally unlike that of any other parasitic copepod, and serves of itself to distinguish the species. 
It does not always follow the exact pattern shown in the figures; but approximated it in 35 out of the 40 females examined. The other five were also distorted, but not symmetrically so.

\section{Chondracanthus sixteni New Species.}

Pl. 3, figs. $27-30 ; 4$, figs, $31-32$.

Host and record of specimens. Six females with egg strings and with attached males were obtained from the inside of the pharynx of a species of halibut at Misaki, Japan, April 25, 1914.

Specific characters of female. General body form short and stout; head distinctly separated from the first thorax segment, longer than wide and somewhat narrowed anteriorly, with the bases of the maxillipeds projecting laterally. All four thorax segments well defined; the first one is the shortest and narrowest and its lateral margins are bluntly pointed; the third one is the longest and widest, with strongly convex sides. The fourth joint is prolonged at its posterior corners into short, stout, and bluntly rounded processes. The genital segment is minute, only about a sixth as wide as the fourth segment, and is sometimes almost hidden by the posterior processes and egg strings. The latter are straight and cylindrical, as long as the entire body and somewhat tapered posteriorly.

The abdomen is one-celled, minute and without anal laminae.

The first antennae are rather long and slender and very indistinctly jointed; the second pair are of the usual form, with stout basal joints and powerful terminal claws. The mandibles are rather large and acuminate and are armed with small but sharp teeth. The cutting blade of the maxillae has a row of teeth along its posterior border, which diminish in size from the tip inwards and wholly disappear at about the center. In the maxillipeds the terminal joint is prolonged inside the base of the claw into a large knob covered with small spines.

Color (preserved material) a uniform yellowish-white.

Total length $6 \mathrm{~mm}$. Greatest width $2 \mathrm{~mm}$. Egg strings $5.75 \mathrm{~mm}$. long. 
Specific characters of male. General body form quite similar to that of the male of $C$. palpifer and $C$. pinguis. The cephalothorax is moderately inflated and is entirely covered by the dorsal carapace. The second, third, and fourth segments are free; the genital segment is acorn-shaped and terminates in a pair of long and acuminate anal laminae. The appendages are like those of the female except that the first maxillae lack the teeth on their posterior margins, and the terminal claws of the second maxillae and maxillipeds are slender and strongly curved. The first and second swimming legs are one-jointed and destitute of setae.

Color (preserved material) a uniform snow-white.

Total length $0.50 \mathrm{~mm}$. Greatest diameter $0.25 \mathrm{~mm}$.

(sixteni, to Dr. Sixten Bock, the collector of these Japanese parasites).

Remarks. This species closely resembles $C$. depressus Scott, C. flurae Kroyer and $C$. soleae Kroyer. Its most distinctive characters are the slender first antennae, the shape of the dorsal surface of the head, the pointed lateral margins of the first thorax segment, the scalloped posterior border of the second segment, and the shape of the mandibles and first maxillae.

\section{Phrixocephalus diversus WiLson.}

Pl. 1, figs. 6-7: 2 , fig. 8 .

Phrixocephalus diversus Wilson, Proceedings U. S. National Museum, vol. 53, p. 77; pl. 10, figs. 86-87.

Host and record of specimens. Two small specimens of a species of Callionymus were captured at a depth of 10 meters near the Zoological station at Misaki, Sagami, Japan. The larger one, $55 \mathrm{~mm}$. long, had two specimens of this parasite fastened in its right eye. The smaller one, $40 \mathrm{~mm}$. in length, had three specimens fastened in its right eye and one in its left eye. The specimens in the right eye of each fish were dissected out, the one in the left eye was not disturbed.

The two from the larger fish were adult females with egg strings. Of the four from the smaller fish, one in each 
eye was an adult female without egg strings, the others were development stages.

This material has proved of peculiar interest for several reasons. The species was originally established upon a single mutilated female and nothing was known of the head and first three thorax segments.

The present specimens fully confirm the establishment of the species and also furnish much information with reference to the habits and life history. In particular they tell us about the mode of attachment and how the parasite gradually assumes its peculiar form.

Mode of attachment. The young parasite, on reaching the requisite stage of development, fastens itself to the outside surface of the fish's eye. It then burrows through the cornea or the sclerotic coat into the interior of the eyeball, passes along the inner wall of the latter to the retina, burrows out through this to its outer surface and spreads its flattened head out over that surface, with its mouth in contact with the network of blood vessels which supply the retina, close to the retinal artery.

From either side of the head profusely branchend soft processes grow out over the back of the retina and hold the head securely in place. At the same time the irritation causes an outgrowth of the surrounding tissue of the eyeball, which spreads over and between the soft processes and covers the head, thus aiding its anchorage.

The point where the parasite first enters the eye eventually comes to be opposite the fourth thorax segment in consequence of the burrowing, and from this segment four chitin horns grow out, which branch more or less profusely and fasten themselves firmly into the wall of the eyeball.

As would naturally be inferred, the separation of one of these parasites from the eye of its host is a very tedious and difficult process, if the specimen is to be secured uninjured.

Specific characters of adult female. Since the original description was made from a mutilated specimen it seems best to revise and enlarge it. Cephalothorax much longer than wide, made up of the head and the first four thorax segments thoroughly fused. Anterior end squarely truncated 
and giving off a cluster of frontal processes, which are soft and many lobed. On the ventral surface on either side a long soft pointed process extends diagonally outward and forward from the bases of the frontal processes. Just behind these and also on the ventral surface is the pair of profusely branched soft horns, which anchor the head to the retina. The base of each horn is wide and strongly flattened dorsoventrally, the two apparently fused across the midline. The rami are also wide and similarly flattened, and most of them are dichotomously branched. The fourth segment is armed with two pairs of large chitin horns, one pair lateral and one ventral.

Each lateral horn is biramose while the ventral horns are triramose. Behind the horns the fourth segment is narrowed into a short chitinized neck, which joins the trunk at a right angle a short distance back of its anterior end. In the original type specimen this junction was not on the midline but removed a little to one side. The same is true of one of the present specimens, but in the others the neck joins the trunk exactly on the midline and thus preserves the symmetry.

Trunk triangular, the dorsal margin nearly straight, the ventral margin strongly convex, these two forming the sides of the triangle and coming together in a rounded knob in front of the base of the neck. The posterior margin or base of the triangle is also nearly straight. The egg strings are attached on either side in front of the posterior margin and close to the dorsal surface. They do not stand out as straight laterally as in the original specimen, but are inclined at an angle of about 45 degrees, and are loosely coiled. The head and thorax are twisted through an angle of 90 degrees, so that the ventral surface faces the side of the trunk.

The antennae and mouth parts are reduced to knobs, the former on the dorsal surface, the latter on the ventral surface, just behind the bases of the frontal processes. The first two pairs of swimming legs are close together behind the flattened bases of the soft horns; the third pair is half way between the soft horns and the chitin horns of the fourth segment; the fourth pair is between the bases of the ventral horns on the fourth segment. The first two pairs are biramose, the rami indistinctly jointed; the third and 
fourth pairs are uniramose, the rami of the third pair indistinctly jointed, those of the fourth pair definitely one-jointed. All the rami are well armed with setae.

Color (preserved material) a yellowish-white; egg strings orange-yellow.

Total length 6.25 $\mathrm{mm}$. Cephalothorax $3 \mathrm{~mm}$. long, 0.80 $\mathrm{mm}$. wide. Trunk $3.40 \mathrm{~mm}$. long, greatest diameter $2.15 \mathrm{~mm}$. Egg coils $3 \mathrm{~mm}$. long.

Specific characters of youngest development stage. Head, thorax, and trunk in the same straight line, the posterior end of the trunk barely protruding from the outer surface of the fish's eye. Cephalothorax much larger than the trunk, about three times as long as wide; frontal processes well formed but much smaller than in the adult and not lobed. Only the flattened bases of the soft horns present, their outer margins showing irregular knobs where the future rami are to develop. The chitin horns on the fourth segment are very short, with the rami indicated by a knob at each distal corner.

The neck behind these horns is only two-fifths the width of the rest of the thorax and is separated from the trunk by a distinct groove.

The trunk is an ellipsoid, the length about twice the greatest diameter, with a pair of tiny anal laminae at the posterior end, each armed with a single seta.

Total length $2.70 \mathrm{~mm}$. Cephalothorax $1.85 \mathrm{~mm}$. long, $0.66 \mathrm{~mm}$. wide. Trunk $0.75 \mathrm{~mm}$. long, $0.40 \mathrm{~mm}$. wide.

Specific characters of older development stage. Cephalothorax bent back at an angle of 45 degrees with the trunk axis, but not twisted sidewise; frontal processes larger and lobed. Soft horns and chitin horns of the fourth segment with short but definite rami. Trunk flattened slightly sidewise, the dorsal margin becoming more straight, the ventral one more convex. Anal laminae still visible at the posterior end near the dorsal surface, but destitute of setae.

Total length $4 \mathrm{~mm}$. Cephalothorax $2.40 \mathrm{~mm}$. long, 0.66 $\mathrm{mm}$. wide. Trunk $1.60 \mathrm{~mm}$. long, $0.66 \mathrm{~mm}$. in greatest diameter.

Remarks. These specimens fully confirm the species and establish it upon a secure basis. This parasite evidently 
seeks the rich blood supply of the retina as its source of food. In reaching this food it burrows twice through the walls of the eyeball, and during this burrowing the cephalothorax develops much more rapidly than the trunk and becomes three times the length of the latter and half as wide again.

At first the trunk does not protrude much beyond the outer surface of the eye and the whole copepod is straight. As soon as the trunk does protrude from the surface of the eye the friction of the water bends it over backwards, and it finally comes to stand at right angles to the axis of the cephalothorax. Further growth of the trunk through the maturing of the reproductive organs pushes its anterior end beyond the base of the neck. Sometimes during this bending and twisting the neck gets pushed to one side of the midline, and the bilateral symmetry is then destroyed.

\section{Antheacheres duebenii M. Sars.}

Antheacheres duebenii M. SARS, Nyt Magazin fur Naturvidenskaberne, vol. 17, part 2, 1870, p. 145; pl. 9, fig. 24-34; pl. 10, fig. $35-53$.

Host and record of specimens. A single undeveloped female, only nine millimeters in length, was obtained from the actinian, Halcurias carlgreni, at the Goto Islands, Kiushiu, Japan, May 15, 1914; depth: 90 fathoms. This corresponds with the young female figured by SARS in the reference given above. 


\section{Explanation of the plates.}

\section{Plate I.}

Fig. 1. Dorsal view of female Argulus caecus. Fig. 2. First and second antennae. Fig. 3. Three of the rods which support the flexible margins of the sucking disks. Fig. 4. Maxilliped. Fig. 5. Respiratory areas. Fig. 6. Young developmental stage of Phrixocephalus diversus. Fig 7. Older stage of same, side view.

\section{Plate II.}

Fig. 8. Adult female Phrixocephalus diversus, dorsal view of head and thorax, side view of trunk. Fig. 9. Adult female Achtheinus japonicus. Fig. 10. Developmental stage of same. Fig. 11. Second antenna. Fig. 12. First maxilla. Fig. 13. Maxilliped. Figs. 14-17. First, second, third and fourth swimming legs.

\section{Plate III.}

Fig. 18. Dorsal view of female Taeniacanthus coelus. Fig. 19. Side view of same. Fig. 20. First antenna. Fig. 21. Second antennae and mouth parts. $a n^{2}$. second antennae; lb. labrum; md. mandible; $m x^{1}$. first maxilla; $\mathrm{mx}^{2}$. second maxilla; mxp. maxilliped. Figs. 22-26. First, second, third, fourth and fifth swimming legs. Fig. 27. Mandible and palp of female Chondracanthus sixteni. Fig. 28. Maxilla of same. Fig. 29. Maxilliped. Fig. 30. Maxilliped of male.

\section{Plate IV.}

Fig. 31. Dorsal view of adult female Chondracanthus sixteni. Fig. 32 Side view of male of same. Fig. 33. Ventral view of adult female Chondracanthus distortus. Fig. 34. Dorsal view of same. Fig. 35. Side view of male. Fig. 36. Second antenna of female. Fig. 37. Mandible and palp. Fig. 38. Maxilla. Fig 39. Maxilliped. 


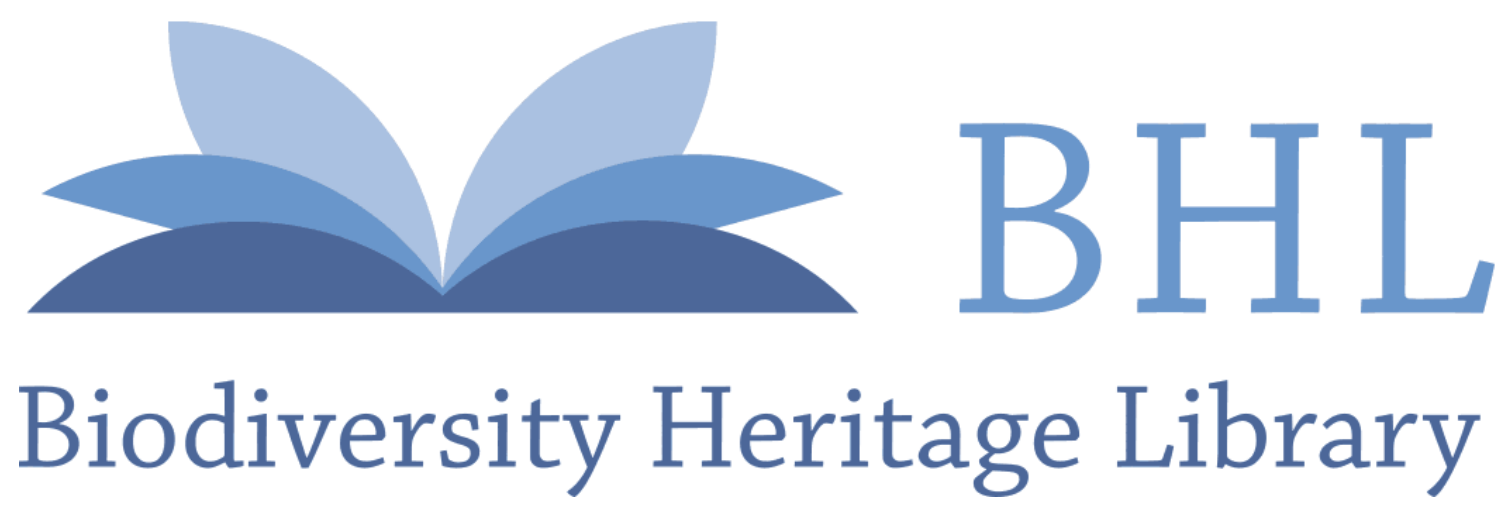

Wilson, Charles Branch. 1922. "Parasitic Copepods from Japan, including five new species." Arkiv för zoologi 14, 1-17. https://doi.org/10.5962/bhl.part.7724.

View This Item Online: https://www.biodiversitylibrary.org/item/30164

DOI: https://doi.org/10.5962/bhl.part.7724

Permalink: https://www.biodiversitylibrary.org/partpdf/7724

\section{Holding Institution}

MBLWHOI Library

Sponsored by

MBLWHOI Library

\section{Copyright \& Reuse}

Copyright Status: NOT_IN_COPYRIGHT

This document was created from content at the Biodiversity Heritage Library, the world's largest open access digital library for biodiversity literature and archives. Visit BHL at https://www.biodiversitylibrary.org. 